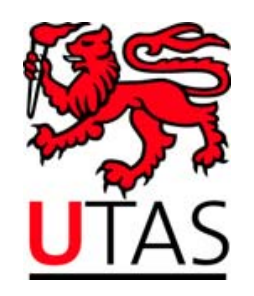

SCHOOL OF ECONOMICS AND FINANCE

Discussion Paper 2011-04

Do Contacts Matter in the Process of Getting a Job in Cameroon?

Firmin Doko Tchatoka

and

Urbain Thierry Yogo

ISSN 1443-8593

ISBN 978-1-86295-614-8 


\title{
Do contacts matter in the process of getting a job in Cameroon?
}

\author{
Firmin Doko Tchatoka* \\ Urbain Thierry Yogo ${ }^{\dagger}$ \\ University of Tasmania \\ CEREG, University of Yaoundé 2
}

February 16, 2011, 6:59pm

*University of Tasmania, School of Economics and Finance; e-mail: Firmin.dokotchatoka@utas.edu.au, homepage: http://www.fdokotchatoka.com/, Tel: +613 6226 1951, Fax:+61 36226 7587, corresponding author

† CEREG, University of Yaoundé 2, e-mail: yogout@gmail.com 


\begin{abstract}
We question whether the use of social networks to exit unemployment matters in Cameroon. We develop a Weibull-type duration model which allows us to address this issue in a convenient way. Our investigations indicate that there is a strong evidence of endogeneity and sample selection biases. We then propose a three-step procedure to deal with both problems. Our results show that the use of social networks to exit unemployment is effective. Furthermore, we find that the hazard monotonically increases with time. Hence, unemployment exhibits a positive duration dependence. Moreover, we provide an analysis of factors that determine labor market participation and the use of social networks. We find that the density of the west native population in the center of Cameroon and religion are the only factors that determine the use of social networks. In contrast, characteristics such as age, sex, education, association's membership, determine labor market participation.
\end{abstract}

Key words: Job search; Cameroon; unemployment; social network; Weibull duration model; threestep procedure.

JEL classification: C35; C36; C41; J64. 


\section{Contents}

1. Introduction 1

2. General framework 2

3. Model for Cameroon $\quad 4$

3.1. Specification and choice of instruments . . . . . . . . . . . . . 4

3.2. Estimation methodology and Data source . . . . . . . . . . . . . 5

4. $\begin{array}{ll}\text { Estimation and results } & \mathbf{7}\end{array}$

4.1. Descriptive statistics and stylized facts . . . . . . . . . . . . . . 7

4.2. Determinants of Job search and the use of informal contacts . . . . . . . . . . . 10

4.3. Duration of unemployment in Cameroon . . . . . . . . . . . . . . 11

$\begin{array}{lll}\text { 5. Conclusions } & 14\end{array}$

\section{List of Tables}

1 Test for weak instruments . . . . . . . . . . . . . . . . 5

2 Search methods among employed and unemployed, 2001-2008 . . . . . . . 8

3 Search methods among employed and unemployed by sex, 2005-2007 . . . . . . 8

4 Kaplan Meir survival an hazard functions . . . . . . . . . . . . . . . . . . . 9

5 Fleming-Harrington Test for Equality of Survivor Functions _ . . . . . . . . . 9

6 Determinants of job search and use of social networks in Cameroon . . . . . . . 11

7 Weibull duration model of unemployment in Cameroon . . . . . . . . . . . . . 13

$8 \quad$ Marginal effects after probit: Determinants of labor market participation . . . . . 17

9 Marginal effects after probit: Determinants of the use of informal contacts . . . . 17 


\section{Introduction}

Finding a job through informal contacts (friends and relatives) seems to be prevalent as a job search method in the labor market. In Cameroon, from 2001 to 2008, 40\% of the unemployed have used this channel while looking for a job (35\% in 2001, 43\% in 2005, 28\% in 2006 and $60 \%$ in 2008). ${ }^{1}$ This reinforces the old "cliché" that who you know is an important means in getting a good job [Mouw (2003)]. Although several studies have established the importance of friends and relatives in the job search process in developed countries [Montgomery (1991)], there is still little evidence on its effects on unemployment duration and the probability of finding a job, at least in low income countries. This raises the following question: do informal contacts (friends and relatives) predominate as a job search method in low income countries? In particular, does this channel matter in the process of getting a job in Cameroon?

The literature on the use of informal contacts as a job search method is now considerable. Two main strands of results emerge from it. The first establishes a positive effect of using friends and relatives on employment, e.g. Granovetter (1974), Holzer (1988), Sylos Labini (2005), Patacchini and Zenou (2008).

Granovetter (1974) addressed this issue in terms of the relationship between the process of getting a job and contacts from survey data [a sample of Newton residents in Massachusetts (USA)]. He found that $43.5 \%$ of technical jobs were found through friends and relatives against $65.4 \%$ of managerial jobs. Several other studies have also reported this channel as the most successful way of exiting unemployment. The problem however, is that most of the conclusions in these studies are drawn from descriptive statistics through survey data. Consequently, the methodology used often fails to explain why the use of friends and relatives is more often chosen by job seekers. Holzer (1988) attempts to answer this question. In his paper, a search model has been developed to show how search methods choice is related to their costs and expected productiveness as well as income (non-wage income and wage offer distributions). The empirical evidence confirmed that social networks are more frequently used than other search methods. Furthermore, Holzer (1988) results also indicated that this channel is more productive in generating offers and acceptances. This is confirmed in the empirical study by Webber (2000) from Austrian data.

The drawback however, is that both Webber (2000) and the previous literature do not address the issue related to the intensity of the job search of the employed in various methodological contexts. The study by Sylos Labini (2005) focuses on this aspect. He concludes that the choice of checking with friends and relatives, even in case of low intensity, could be more effective. Nevertheless, this effectiveness could depend on the ties (weak or strong). This aspect is not taken into account in the analysis by Sylos Labini (2005). Patacchini and Zenou (2008) analyzed the effects of strong and weak ties on the individual probability of finding a job. From the dynamic model of CalvóArmengol and Jackson (2004), they found that the individual probability of finding a job increases with the number of strong and weak ties. More precisely, the longer the length of the ties, the lower the effect.

Even though the previous literature appears to be highly in favor of a positive effect of the use of informal contacts as a strategy on the probability of finding a job, it is not unanimous. A

\footnotetext{
${ }^{1}$ These statistics are provided by the surveys of the National Institute of Statistic (ECAM1 2001, EESI 2005 and EDIJ 2008).
} 
second literature against the effectiveness of this positive effect has emerged. The pioneers of this strand include Addison and Portugal (2001), Cahuc and Fontaine (2002), and Calvó-Armengol and Jackson (2004). Addison and Portugal (2001) investigated the effects of job search methods on the escape rate from unemployment using Portuguese data. They found that although the use of social networks is more popular as a job search method, it has no significant effect on the probability of getting out of unemployment. The authors then deduced that sometimes, social networks can be under- or over-utilized, leading to market inefficiency. Cahuc and Fontaine (2002) provided a simple matching model in which unemployed workers and employers could be matched together through social networks and more (costly) efficient methods. They showed that in a decentralized equilibrium, social networks can be over-or under-utilized. Clearly, there is no consensus about whether the use of social networks matters or not in the process of getting the job.

However, despite this growing literature, not much is known about low income countries in general, and Cameroon in particular. This paper aims to fulfill this gap by addressing whether the use of informal contacts (friends and relatives) influences the probability of exiting unemployment in Cameroon. Our empirical investigations uses the Weibull-type discrete time duration model. The novelty of our analysis lies in its attempt to deal with both endogeneity and selection biases. Most of the literature mentioned above focus on only the endogeneity bias. This paper is the first that targets both problems simultaneously. We have developed statistical tools to reinforce our analysis. In this vein, we propose a procedure for selecting strong and valid instruments by resorting to Stock and Yogo (2005)'s weak instruments test, and Sargan and $J$ tests for overdentification restrictions. Our results clearly indicate that endogeneity and sample selection biases are issues which need to be corrected. We then propose a three-step procedure which allows us to deal with both problems. We find that the use of social networks (friends and relatives) is effective in the process of getting out of unemployment and that unemployment exhibits a positive duration dependence in Cameroon.

The remainder of the paper is organized as follows. Section 2 presents the general framework. Section 3 details the model for Cameroon. Section 4 presents the estimations, and the conclusions are drawn in Section 5.

\section{General framework}

We consider the following discrete time duration model of unemployment governed by the Weibull type-distribution with density:

$$
f\left(t_{i}\right)=\tau \lambda_{i}^{\tau} t^{\tau-1} \exp \left[-\left(\lambda_{i} t\right)^{\tau}\right], i=1,2, \ldots, N
$$

where $T_{i}$ is a random variable that measures the duration of unemployment of individual $i$, $\lambda_{i} \equiv \lambda_{i}(\theta)=\exp \left[\mathrm{m}_{i}(\theta)\right], \mathrm{m}_{i}(\theta)$ is a function of both structural parameters $\theta$ and individual characteristics such as age, sex, marital status and variables related to the use of social networks in the job search process(friends and relatives), and $\tau>0$ is a constant. Then, the Weibull hazard and survival functions associated with (2.1) are given by:

$$
\begin{aligned}
h_{i}(t) & =\tau t^{\tau-1} \exp \left[\tau \mathrm{m}_{i}(\theta)\right], \\
S_{i}(t) & =\exp \left\{-t^{\tau} \exp \left[\tau \mathrm{m}_{i}(\theta)\right]\right\}, i=1,2, \ldots, N .
\end{aligned}
$$


where $\tau$ is an unknown coefficient and $\exp ($.$) refers to the exponential function. The hazard rate in$ (2.2) is decomposed into a baseline component that depends only on $t, h_{0}(t)=\tau t^{\tau-1}$ and a second term $\exp \left[\tau \mathrm{m}_{i}(\theta)\right]$ that is parameterized as a function of covariates only.

Define

$$
\varepsilon_{i}=\frac{1}{\sigma}\left[\ln \left(t_{i}\right)+\mathrm{m}_{i}(\theta)\right], i=1,2, \ldots, N,
$$

where $\varepsilon_{i}, i=1,2, \ldots, N$ are error terms and $\tau^{-1}=\sigma$. So, (2.4) can be reformulated as:

$$
\ln \left(t_{i}\right)=-\mathrm{m}_{i}(\theta)+\sigma \varepsilon_{i}, i=1,2, \ldots, N,
$$

If $\varepsilon_{i}$, are independent of $\mathrm{m}_{i}(\theta)$ for $i=1,2, \ldots, N$, then we can show that the $\varepsilon_{i}$ have the probability density given by $f\left(\varepsilon_{i}\right)=\exp \left(\varepsilon_{i}-e^{\varepsilon_{i}}\right)$, i.e. the $\varepsilon_{i}$ are type 1 extreme value errors. But this property does not hold if $\varepsilon_{i}$ are correlated with $\mathrm{m}_{i}(\theta)$. Furthermore, under (2.5), the probability density of $y_{i}=\ln \left(t_{i}\right)$ is $f\left(y_{i}\right)=\sigma^{-1} f\left(\varepsilon_{i}\right)$. We can then estimate model (2.5) instead of (2.2).

In the literature, three specifications are often used for modeling duration: parametric, semiparametric and non parametric. Although the semi-parametric specification seems to be more widely used in empirical work, we choose the specification (2.1) since it is a relatively simple way to capture duration dependence. For example, it allows us to test for duration dependence [ see Calvó-Armengol and Jackson (2004)] and introduces heterogeneity between individuals through their own characteristics. If $\tau=1$ in (2.2), the Weibull distribution reduces to exponential one and the hazard only depends on individual characteristics over time. If $\tau>1$, the hazard monotonically increases with $t$ and unemployment exhibits a positive duration dependence. The intensity of this dependence however, varies between individuals. Hence, the probability of exiting unemployment increases with time spent in unemployment, but its marginal effects vary between individuals. For example, if two individuals $i$ and $j$ have similar characteristics but different ages, they should have different probabilities of exiting unemployment. Finally, if $\tau<1$, the hazard monotonically decreases.

Suppose that we have the estimates of $\tau$ and $\theta$, say $\hat{\tau}$ and $\hat{\theta}$. Then, the hazard function can be estimated by $\hat{h}_{i}(t)=\hat{\tau} t^{\hat{\tau}-1} \exp \left[\hat{\tau} \mathrm{m}_{i}(\hat{\theta})\right], i=1,2, \ldots, N$. The question is how to estimate $\tau$ and $\theta$ consistently. Usually, the maximum likelihood (ML) method is applied for the estimation. However, this method produces inconsistent estimates if the $\varepsilon_{i}$ are correlated with $\mathrm{m}_{i}(\theta)$. In our case, assuming the exogeneity of $\mathrm{m}_{i}(\theta)$ is problematic. Hence, the ML procedure needs to be reinforced. According to the literature related to social networks and labor markets [Holzer (1988), Addison and Portugal (2001) and Mouw (2003)], the choice of using the social networks [which is part of $\mathrm{m}_{i}(\theta)$ ] in getting a job is endogenous. Many factors may explain this endogeneity, notably, location, gender and matrimonial status. To estimate $\tau$ and $\theta$ consistently, one can resort to the instrumental variables (IV) method. To use the IV method, we must find suitable instruments (valid and strong) for the measure of the use of social networks (friends and relatives). If the available instruments are strong, the endogeneity bias problem can be solved. Statistical difficulties however, arise when the available instruments are weak, i.e. poorly correlated with the (supposedly) endogenous regressors. It is well known in econometrics that when instruments are weak, IV method produces biased and inconsistent estimates and standard test procedures, like Wald, Student $t$, Lagrange multiplier and Likelihood ratio, become unreliable [see Dufour (1997, 2003), Staiger and Stock (1997), Wang and 
Zivot (1998), Stock, Wright and Yogo (2002), Hall, Rudebusch and Wilcox (1996), Hall and Peixe (2003), Doko and Dufour (2008)].

Moreover, even though the endogeneity bias can be dealt with by resorting to the IV method, another source of endogeneity unfortunately arises from sample selection. Indeed, the use of friends and relatives is only observed for peoples who have a job or are looking for a job. This leads to sample censoring, and hence strong evidence of sample selection bias. To avoid this problem, we propose a three-step estimation procedure (see Section 3.2 for further details). To our knowledge, this paper is the first which attempts to challenge simultaneously both: endogeneity and sample selection biases. Standard job search models often focus on the endogeneity bias, ignoring the issue related to sample selection.

Section 3 details the specification of our model for Cameroon, the choice of instruments and the methodology of estimation.

\section{Model for Cameroon}

This section specifies the model for Cameroon, discusses the choice of instruments and the methodology of estimation that is proposed.

\subsection{Specification and choice of instruments}

We consider the following specification of model (2.5):

$$
\ln \left(t_{i}\right)=-\theta_{0}-\theta_{1} \operatorname{Parel}_{i}-\sum_{j=2}^{k} X_{i j} \theta_{j}+\sigma \varepsilon_{i}, i=1,2, \ldots, N,
$$

where for all $j=1, \ldots, k$, Parel is a binary variable (supposedly endogenous) that measures the use of social network (friends and relatives) in the process of job search, $X$ is the matrix of individual characteristics given by:

$X=[$ Schg, Schte, Age, Sex, Mar, Prim, Ass, Parel.Age, Parel.Sex, Parel.Schg, Parel.Schte $]$,(3.2)

where Age is the age of the individual at the time of survey, Schg refers to secondary education (general) and Schte refers to secondary education (technical), Sex is the sex, which takes 1 if $i$ is a man and 0 otherwise, Mar refers to marital status, which takes 1 if $i$ is married (including monogamous) and 0 otherwise, Ass refers to association membership, which takes 1 if $i$ belongs to an association and 0 otherwise, Prim refers to primary education, and $\theta_{j}, j=0, \ldots, 11$, are unknown coefficients to be estimated. From ( 3.1 ), the hazard function (2.2) is now:

$$
h_{i}(t)=\tau t^{\tau-1} \exp \left[\tau\left(\theta_{0}+\theta_{1} \operatorname{Parel}_{i}+\sum_{j=2}^{k} X_{i j} \theta_{j}\right)\right], i=1,2, \ldots, N,
$$

To deal with the endogeneity of Parel, the following instruments are suggested according to the literature:

$$
Z=[\text { Prot, Fwk, Mst, Dst, Fst }] \text {. }
$$


The variable Prot takes 1 if $i$ is a Protestant and 0 otherwise, Fwk refers to father's work and takes 1 if the father of $i$ has a job and 0 otherwise, Mst takes 1 if the mother of the job seeker is a senior executive and 0 otherwise, Dst is the density of the west native population in the center, and Fst takes 1 if the father of the job seeker is a senior executive and 0 otherwise. The choice of Prot as an instrument is justified by the fact that church membership more often implies the possibility of benefit from the support of the community via a financial or social assistance. This view is supported by Weber (1905), Hansen and Hansen (2008) and Ndongo, Ebene and Tegnerowicz (2006) in the context of Cameroon. The variables Fwk, Mst and Fst are related to the status of the job seeker's parents' employment. These variables are often quoted in the literature as proxies of social capital [see for example Coleman $(1988,1990)]$. The variable Dst is used as an instrument of the measure of the use of social network in Wahba and Zenou (2004). Since all these instruments except Dst are binary, they may be weak, hence poorly correlated with Parel. In this case, the parameter will be weakly identified and the estimates biased. We use the weak instruments test proposed by Stock and Yogo (2005) to access whether these instruments are strong or not. Our results are presented in Table 1.

Table 1. Test for weak instruments

\begin{tabular}{c|ccc}
\hline \hline Instruments & Cragg \& Donald Wald-F-Statistic & Critical value & IV size of relative bias \\
\hline Dst\&Fst & 15.07 & 16.38 & $10 \%$ \\
Dst & 22.84 & 8.96 & $15 \%$ \\
Fst & 1.71 & 6.66 & $20 \%$ \\
Mst & 0.001 & 5.53 & $25 \%$ \\
Fwk & 0.95 & & \\
Prot & 3.34 & & \\
\hline \hline
\end{tabular}

Note: instrument is weak if the Cragg \& Donald statistic is below the critical value according to the IV size of relative bias.

Excepting the density of the west native population in the center of Cameroon (here Dst) and the combination of Dst with the father's occupational status (Fst), the Stock and Yogo (2005) test does not reject the null hypothesis of weak instruments for the other IVs. Since there is only one endogenous variable, we are able to identify model parameters. The Sargan and J tests for overdentification restrictions confirmed that the above instruments are valid. The p-value of both tests is as great as 0.97 , indicating that the null hypothesis of overdentification restrictions could not be rejected. We now discuss the estimation methodology to overcome both endogeneity and sample selection biases.

\subsection{Estimation methodology and Data source}

This section explains our estimation methodology and describes the source of the data used. As mentioned in the previous section, there are two problems that can introduce biases. The first is due 
to the endogeneity of Parel and the second, the way the sample is selected (non-randomly). To deal with both problems, we propose the following three step-procedure:

\section{Step 1}

We estimate a job search model and recover the predicted values of the inverse Mills Ratio IMRp. The Job search model is specified as:

$$
\operatorname{Ljob}_{i}=\beta_{0}+\sum_{j=1}^{7} X_{i j} \beta_{j}+\sum_{m=1}^{5} Z_{i m} \pi_{m}+v_{i}, i=1,2, \ldots, N,
$$

where $\operatorname{Ljob}_{i}$ is a binary variable that takes 1 if the individual has been looking for a job or have been working at least one week before the survey, $X_{i j}, j=1, \ldots, 7$ are the first seven variables in $X$ (where covariates are excluded), $Z_{i m}, m=1, \ldots, 5$ are the excluded instruments, $v_{i}$ are the error terms and $\beta_{j}, j=1, \ldots, 7, \pi_{m}, m=1, \ldots, 5$ are unknown coefficient to be estimated. Since the dependent variable Ljob is binary, we use a probit for (3.5) that we compare with the linear probability method. The inverse Mill ratio is then recovered by:

$$
\operatorname{IMRp}_{i}=\frac{\phi\left(\hat{\beta}_{0}+\sum_{j=1}^{7} X_{i j} \hat{\beta}_{j}+\sum_{m=1}^{5} Z_{i m} \hat{\pi}_{m}\right)}{\Phi\left(\hat{\beta}_{0}+\sum_{j=1}^{7} X_{i j} \hat{\beta}_{j}+\sum_{m=1}^{5} Z_{i m} \hat{\pi}_{m}\right)}, i=1, \ldots, N
$$

where $\hat{\beta}=\left(\hat{\beta}_{j}\right)_{j=0, \ldots, 7}$, and $\hat{\pi}=\left(\hat{\pi}_{m}\right)_{m=1, \ldots, 5}$, are the maximum likelihood estimates of $\pi, \phi($. refers to the density of a standardized normal distribution while $\Phi($.$) is its cumulative function.$

\section{Step 2}

We estimate the model of the use of social network (friends and relatives) by introducing IMRp as additional explanatory variable to correct the sample selection bias (if any). The model is specified explicitly as:

$$
\operatorname{Parel}_{i}=\gamma_{0}+\sum_{j=1}^{11} X_{i j} \gamma_{j}+\sum_{m=1}^{5} Z_{i m} \phi_{m}+\operatorname{IMRp}_{i} \alpha+u_{i}, i=1,2, \ldots, N,
$$

where $X$ is the included instruments and $Z$ the excluded instruments. Again, the dependent variable Parel is binary. Then, we use the probit estimation that we compare with OLS (linear probabilities). The predictions for Parel are recovered by:

$$
\operatorname{Parelp}_{i}=\hat{\gamma}_{0}+\sum_{j=2}^{11} X_{i j} \hat{\gamma}_{j}+\sum_{m=2}^{5} Z_{i m} \hat{\phi}_{m}+\operatorname{IMRp}_{i} \hat{\alpha}, i=1,2, \ldots, N
$$

\section{Step 3}

Finally, we replace Parel by Parelp in model (3.1) and estimate it by the maximum likelihood (ML) using (2.5) which is an equivalent formulation of model (2.1). The log-likelihood of the model is then given by:

$$
\mathscr{L}(\theta, \tau \mid \tilde{X})=\sum_{i=1}^{N} \ln \left[f\left(y_{i}\right)\right]=\sum_{i=1}^{N}\left\{\ln (\tau)+\tau\left[\ln \left(t_{i}\right)+m_{i}(\theta)\right]-\exp \left[\tau\left(\ln \left(t_{i}\right)+m_{i}(\theta)\right)\right]\right\},
$$




$$
m_{i}(\theta)=\theta_{0}+\theta_{1} \operatorname{Parelp}_{i}+\sum_{j=2}^{k} X_{i j} \theta_{j}, \tau=\sigma^{-1}, \tilde{X}=[\text { Parelp, } X]
$$

The maximization problem is $\max _{\{\theta, \sigma\}} \mathscr{L}(\theta, \tau, \tilde{X})$ with respect to $\theta$ and $\tau$. The first order conditions of this problem are given by:

$$
\begin{aligned}
\left.\frac{\partial \mathscr{L}}{\partial \theta}\right|_{(\hat{\theta}, \hat{\tau})} & =\sum_{i=1}^{N}\left[1-\exp \left(\hat{\tau} m_{i}(\hat{\theta})\right) t_{i}^{\hat{\tau}}\right] \tilde{X}_{i}=0 \\
\left.\frac{\partial \mathscr{L}}{\partial \tau}\right|_{(\hat{\theta}, \hat{\tau})} & =\frac{N}{\hat{\tau}}+\sum_{i=1}^{N}\left[1-\exp \left(\hat{\tau} m_{i}(\hat{\theta})\right) t_{i}^{\hat{\tau}}\right]\left[\ln \left(t_{i}\right)+m_{i}(\hat{\theta})\right]=0 \\
& =\frac{N}{\hat{\tau}}+\sum_{i=1}^{N} \ln \left(t_{i}\right)\left[1-\exp \left(\hat{\tau} m_{i}(\hat{\theta})\right) t_{i}^{\hat{\tau}}\right]=0
\end{aligned}
$$

where $\tilde{X}_{i}=\left[\operatorname{Parelp}_{i}, X_{i}\right]$ and $m_{i}(\theta)=\tilde{X}_{i} \theta$. Note that (3.12) holds because (3.10) implies that $\sum_{i=1}^{N}\left[1-\exp \left(\hat{\tau} m_{i}(\hat{\theta})\right) t_{i}^{\hat{\tau}}\right] m_{i}(\hat{\theta})=0$. We have used Stata 11.1 to solve the problem. The details of the results are presented in the next section.

The data used are drawn from the Youth Labor Market Incorporation Survey (EDIJ). This survey is carried out annually among the youth in the city of Yaoundé, Cameroon. The 2008 survey was conducted among 1924 youths. In this survey, eight categories of job search were considered: direct application by unemployed workers to firms, informal methods (friends and relatives), self employment, use of a public employment agency, use of a private employment agency, state hiring, and a residual group (other methods). Additional information drawn from the survey included variables such as sex, age, marital status, father and mother employment tenure, wage, region of residence, and religion.

\section{Estimation and results}

This section presents our results following the three-step procedure describes in the previous section. The section is organized into three subsections. The first provides descriptive statistics and stylized facts of job search in Cameroon. The second estimates the job search and use of social net work (friends and relatives) models. Finally, the third estimates the duration model. Section 4.1 summarize some descriptive statistics and stylized facts.

\subsection{Descriptive statistics and stylized facts}

This section presents some descriptive statistics and stylized facts related to the job search process and the use of social networks in Cameroon. Table 2 contains the distribution of employed and unemployed workers by job search method from 2001 to 2008 . We note that the use of friends and relatives to find a job has increased. $41.5 \%$ of unemployed workers have used informal contacts (friends and relatives) when looking for a job. This proportion was 35\% in 2001, 43\% in 2005 and $60 \%$ in 2008. Note that the $60 \%$ in 2008 is for Yaoundé only. Moreover, $41 \%$ of employed workers have declared that they found their job through friends and relatives. This proportion is relatively 
high compared with other job search methods.

\begin{tabular}{|c|c|c|c|c|c|}
\hline \multirow[t]{2}{*}{ Job Search Method } & \multicolumn{4}{|c|}{ Unemployed } & \multirow{2}{*}{$\begin{array}{c}\text { Employed } \\
2008 \\
\end{array}$} \\
\hline & 2001 & 2005 & 2006 & 2008-Yaoundé only & \\
\hline Direct application & 42 & 24 & 34 & 10 & 11.42 \\
\hline Parents and relatives & 35 & 43 & 28 & 60 & 41 \\
\hline Public agency & 7 & 2 & 11 & - & - \\
\hline Private agency & 6 & .12 & 4 & 0 & 5.71 \\
\hline State selection & 8 & 5 & 7 & 0 & 12.85 \\
\hline Self-employment & - & - & 2 & 5 & 19 \\
\hline Other & 2 & 1 & 9 & - & 3 \\
\hline No mean & & 18 & - & & \\
\hline
\end{tabular}

Source : INS-Cameroon.

We also compared the use of friends and relatives as a job search method between women and men, as seen in Table 3. In general, women used informal contacts (friends and relatives) more often than men. The proportions were $36.9 \%$ and $46.3 \%$ for women compared with $38.9 \%$ and $31 \%$ for men, in 2005 and 2007 respectively.

\begin{tabular}{|c|c|c|c|c|}
\hline \multirow[t]{2}{*}{ Job Search Method } & \multicolumn{2}{|c|}{ Women } & \multicolumn{2}{|c|}{ Men } \\
\hline & 2005 & 2007 & 2005 & 2007 \\
\hline Direct application & 7.3 & 12.2 & 28.4 & 45.5 \\
\hline Parents and relatives & 36.9 & 46.3 & 38.9 & 31 \\
\hline Public agency & .9 & 1 & 5.9 & 8.7 \\
\hline Private agency & .1 & .2 & 5.2 & 6.4 \\
\hline State selection & 5.4 & 9 & 10.2 & 6.2 \\
\hline other including Self-employment & .7 & 1 & 1.6 & .8 \\
\hline
\end{tabular}

Source : INS-Cameroon.

Table 4 presents the Kaplan-Meier non parametric survival and smoothed hazard estimates by job search methods. We note that the estimated survival curves for all search methods decline rapidly at first and then decline slowly. Furthermore, except for private competition, the estimated survival curves seem homogenous for other search methods. The survival hazard estimated is low for direct application and high for private application compared to other methods. Which means that the probability of exiting unemployment between $t$ and $t+1$ is low for direct application and high for private application, compared to other methods including informal contacts. As we can 
see, the smooth hazard curve for informal contacts (friends and relatives) begins to increase after ten time periods. This suggests that the probability of exiting unemployment using this channel is not negligible.

Table 4. Kaplan Meir survival an hazard functions

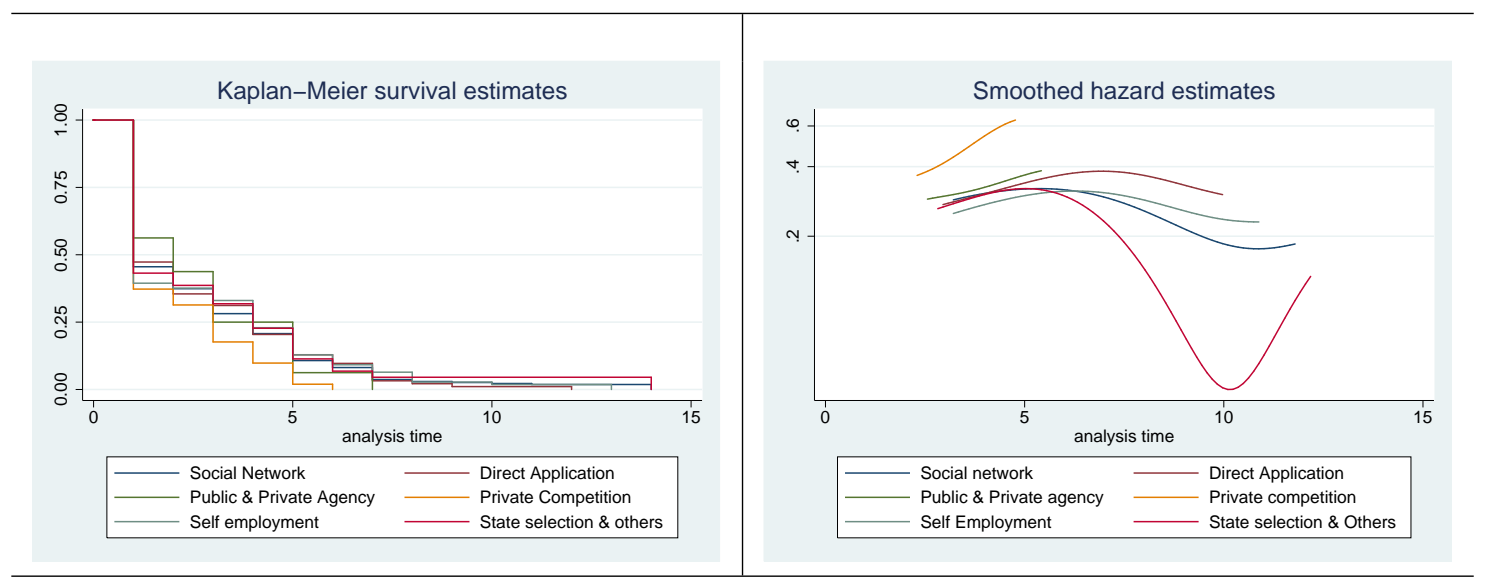

To confirm whether there is a difference between survival and hazard functions among all search methods, we have used the Fleming and Harrington (1982) test [see Table 5].

Table 5. Fleming-Harrington Test for Equality of Survivor Functions

\begin{tabular}{cccc}
\hline \hline Job Search Method & Events Observed & Events Expected & Sum of Log Ranks \\
\hline Direct application & 93 & 93.42 & 0.510 \\
Social network & 270 & 273.83 & 0.694 \\
Public and private agency & 16 & 15.42 & 0.750 \\
Private competition & 51 & 40.41 & 2.596 \\
State selection and other & 44 & 47.24 & -0.892 \\
Self employment & 109 & 112.28 & -3.660 \\
Prob $>\chi^{2}$ & 0.06 & 0.06 & 0.06 \\
Total & 583 & 583.00 & 0 \\
\hline \hline
\end{tabular}

This test is one of the several non parametric tests that are often used to compare survival functions across experiences [see Mantel and Haenszel (1959, log rank test), Breslow (1970, Wilcoxontype test), Peto and Peto (1972), Prentice (1978) and Tarone and Ware (1977)]. We chose this test because it freely uses the way the weights are chosen for individuals at the failure time. The test cannot reject the equality of survival functions at the conventional level of $5 \%$, but does at the nominal level greater than $6 \%$. In particular, the equality of survival functions is rejected at $10 \%$. We now proceed to the parametric estimation in Section 4.2 and 4.3 below. 


\subsection{Determinants of Job search and the use of informal contacts}

This subsection provides empirical estimates of two models: the job search model described by (3.5) and the model of the use of informal contacts (friends and relatives) in the job search process characterized by (3.7). The job search model aims to determine factors that explain labor market participation in Cameroon, while the second model questions whether the use of social networks in the process of getting out of unemployment matters. Table 6 present the results of our estimations. In the first column we report the variables, while in the other columns we report probit and linear probability estimations for each model. Our results do not vary substantially between probit and linear probability methods. As mentioned earlier, the estimation of the job search model can help to deal with selection bias. The selection bias arises because the choice of the sample of individuals who use social networks is not random. As expected from the labor market literature, the estimates of the coefficients of age, sex, education are statistically significant even at the $1 \%$ level. These variables positively affect the probability of market participation. For example, we can see from the linear probability estimates that a one-unit increase in age increases the probability of looking for a job by $3.2 \%$. The effects of a secondary technical or primary education on the the probability of looking for a job is greater than those of a secondary general education. This is justified mainly by the predominance of informal activities which do not require high skills. Furthermore, membership to an association also significantly and positively influences the probability of looking for a job. This result may be justified by the fact that many activities in Cameroon are often initiated by ethnic groups. These results are confirmed by the marginal effects of individual characteristics presented in Table 8 in the Appendix.

Moreover, it is important to note that this estimation contributes to correct the endogeneity bias. Indeed, the inverse Mills ratio is constructed from this estimation and is added as a factor that determines the use of the social networks. The last two columns of Table 6 provides the results of the estimation of model (3.7). The mains objective is to deal with the issue related to the endogeneity of the measure of the use of social networks. Our estimation also aims to reinforce some stylized facts about the determinants of the choice of using social networks. As above, two methods are provided: probit and linear probability. As can be seen, the density of the west native population in the center of Cameroon (here Dst) and the religion (here Protestant) are the only excluded instruments from (3.1) that determine the use of social networks. The other excluded instruments, such as characteristics related to parental employment status are weak (i.e. poorly related to the measure of the use of social networks). The Stock and Yogo (2005) weak instrument test did not find evidence of a strong correlation between religion and use of social networks. This is not surprising since this test is conservative. One explanation of this high correlation is that church membership often implies the possibility of benefiting from the support of the community via financial or social assistance.

The density of the west native population in the center of Cameroon positively affects the choice of using social networks. This result is similar to Putnam (2000) and Wahba and Zenou (2004) who argued that high density living often increases social interaction, network solidarities, and consequently social networks. Moreover, most of the included instruments (except "sex" whose coefficient is not significant for both either probit and linear probabilities methods) determine the use of social networks. We then observe that individuals with high education are less likely to use social networks than those with low education. This result is confirmed by a $t$-test for the equality of the coefficients between primary and secondary general education or between primary 
Table 6. Determinants of job search and use of social networks in Cameroon

\begin{tabular}{|c|c|c|c|c|}
\hline \multirow[t]{2}{*}{ Variables } & \multicolumn{2}{|c|}{ job search model } & \multicolumn{2}{|c|}{ use of social networks } \\
\hline & Probit & Linear Prob & Probit & Linear Prob \\
\hline Age & $\begin{array}{c}0.100^{* * *} \\
(0.009)\end{array}$ & $\begin{array}{c}0.032^{* * *} \\
(0.003)\end{array}$ & $\begin{array}{c}-0.019^{* *} \\
(0.008)\end{array}$ & $\begin{array}{c}0.004 \\
(0.003)\end{array}$ \\
\hline Sex & $\begin{array}{c}0.35^{* * *} \\
(0.074)\end{array}$ & $\begin{array}{c}0.105^{* * *} \\
(0.021)\end{array}$ & $\begin{array}{l}-0.090 \\
(0.129)\end{array}$ & $\begin{array}{c}0.006 \\
(0.049)\end{array}$ \\
\hline Mar & $\begin{array}{c}0.049 \\
(0.119)\end{array}$ & $\begin{array}{c}0.025 \\
(0.040)\end{array}$ & $\begin{array}{c}-0.276^{*} \\
(0.163)\end{array}$ & $\begin{array}{l}-0.098 \\
(0.060)\end{array}$ \\
\hline Prim & $\begin{array}{c}0.809^{* * *} \\
(0.148)\end{array}$ & $\begin{array}{c}0.275^{* * *} \\
(0.048)\end{array}$ & $\begin{array}{c}0.518^{* * *} \\
(0.198)\end{array}$ & $\begin{array}{c}0.269^{* * *} \\
(0.073)\end{array}$ \\
\hline Schg & $\begin{array}{c}0.216^{* * *} \\
(0.091)\end{array}$ & $\begin{array}{c}0.0 .084^{* * *} \\
(0.028)\end{array}$ & $\begin{array}{c}0.214 \\
(0.154)\end{array}$ & $\begin{array}{l}0.097^{*} \\
(0.058)\end{array}$ \\
\hline Schte & $\begin{array}{c}0.496^{* * *} \\
(0.115)\end{array}$ & $\begin{array}{c}0.168^{* * *} \\
(0.037)\end{array}$ & $\begin{array}{c}0.204 \\
(0.184)\end{array}$ & $\begin{array}{l}0.125^{*} \\
(0.070)\end{array}$ \\
\hline Ass & $\begin{array}{c}0.306^{* * *} \\
(0.077)\end{array}$ & $\begin{array}{c}0.095^{* * *} \\
(0.025)\end{array}$ & $\begin{array}{c}0.258^{* *} \\
(0.130)\end{array}$ & $\begin{array}{c}0.124^{* *} \\
(0.049)\end{array}$ \\
\hline Prot & $\begin{array}{c}0.059 \\
(0.088)\end{array}$ & $\begin{array}{c}0.023 \\
(0.026)\end{array}$ & $\begin{array}{c}0.347^{* *} \\
(0.150)\end{array}$ & $\begin{array}{c}0.133^{* *} \\
(0.056)\end{array}$ \\
\hline Fwk & $\begin{array}{l}-0.053 \\
(0.079)\end{array}$ & $\begin{array}{l}-0.016 \\
(0.025)\end{array}$ & $\begin{array}{l}-0.079 \\
(0.134)\end{array}$ & $\begin{array}{l}-0.035 \\
(0.050)\end{array}$ \\
\hline Mst & $\begin{array}{c}-0.03 \\
(0.122)\end{array}$ & $\begin{array}{l}-0.005 \\
(0.034)\end{array}$ & $\begin{array}{c}0.141 \\
(0.226)\end{array}$ & $\begin{array}{c}0.052 \\
(0.086)\end{array}$ \\
\hline Dst & $\begin{array}{c}-0.086 \\
(0.187)\end{array}$ & $\begin{array}{l}-0.033 \\
(0.052)\end{array}$ & $\begin{array}{c}1.100^{* * *} \\
(0.363)\end{array}$ & $\begin{array}{c}0.328^{* * *} \\
(0.112)\end{array}$ \\
\hline Fst & $\begin{array}{c}0.038 \\
(0.079)\end{array}$ & $\begin{array}{c}0.009 \\
(0.023)\end{array}$ & $\begin{array}{c}0.165 \\
(0.142)\end{array}$ & $\begin{array}{c}0.067 \\
(0.054)\end{array}$ \\
\hline Constant & $\begin{array}{c}-3.431^{* * *} \\
(0.255)\end{array}$ & $\begin{array}{c}-0.613^{* * *} \\
(0.072)\end{array}$ & $\begin{array}{l}- \\
-\end{array}$ & - \\
\hline IRMp & $\begin{array}{l}- \\
-\end{array}$ & $\begin{array}{l}- \\
-\end{array}$ & $\begin{array}{c}0.234^{+} \\
(0.149)\end{array}$ & $\begin{array}{c}0.248^{* * *} \\
(0.056)\end{array}$ \\
\hline Log pseudolikelihood & -794.77 & - & -277.83 & - \\
\hline $\operatorname{Prob}>\chi^{2}$ & 0.000 & - & 0.000 & - \\
\hline R-squared & - & 0.191 & - & 0.547 \\
\hline Number of observations & 1532 & 1532 & 430 & 430 \\
\hline
\end{tabular}

$* * *-$ p-val $<0.01, * *-$ p-val $<0.05, *-$ p-val $<0.1,+$ p-val $<0.12$, and numbers in $()-$. robust standard errors.

and secondary technical. This is probably because individuals with primary education in Cameroon often do not rely heavily on their human capital. So, they prefer to resort to social networks in order to get a job. The resort to social networks comes as a compensation for a lack of human capital, mainly in fields where high qualifications are not required. In addition, the inverse Mills ratio has a positive coefficient [its p-value is $11.6 \%$ for the probit estimation column 2 and 0.00 for linear probabilities, see Table 6]. This suggests that there is a selection bias that has been corrected. The marginal effects of all these variables are shown in Table 9 in the Appendix. Section 4.3 now presents the estimation of the duration model.

\subsection{Duration of unemployment in Cameroon}

This subsection provides the results from estimation of model (3.1). Three methods are used for the purpose of comparison. The main method is Weibull as previously explained. The other two are the standard two stage least squares (2SLS) and ordinary least squares $\left(\mathrm{OLS}^{++}\right)$. In the Weibull 
estimation, we distinguish three setups: (i) $\mathrm{WI}^{++}$where the measure of the use of social networks (here Parel) is treated as exogenous, (ii) $\mathrm{WII}_{1}$ where Parel is endogenous and is replaced by its prediction from the probit estimation above, (iii) $\mathrm{WII}_{2}$ whereParel is endogenous and is replaced by its prediction from the linear probability estimation. For the 2SLS method, we also consider cases (ii) and (iii) that we have named $\mathrm{SII}_{1}$ and $\mathrm{SII}_{2}$ respectively. Strictly speaking, covering a large spectrum of methods allows us to widely assess the central question about whether informal contacts matter or not in the process of exiting unemployment.

Table 7 reports the results. First, we note in setups $\mathrm{OLS}^{++}$and $\mathrm{WI}^{++}$where the variable that measures the use of social networks is treated as exogenous, its coefficient is not statistically significant. However, when this variable is instrumented, its coefficient becomes statistically significant and positive at $5 \%$ for the Weibull estimation and $10 \%$ for the 2SLS estimation. This result underscores clearly that endogeneity was an issue that has been corrected. Hence, treating the variable that measures the use of social networks as exogenous, or not correcting for the sample selection bias, is misleading. Moreover, since the coefficient of the measure of social networks in the process of job search is positive, the hazard decreases with this variable. This means that individuals who use social networks are likely to exit unemployment earlier than those who do not. This result confirms our previous stylized facts.

Furthermore, we observe that most individual characteristics such as sex, education, and membership to an association, do not affect the hazard rate, since their coefficients are not statistically significant. Clearly, being a woman, highly educated or a member of an association do not provide any advantage from the use of social networks in finding a job. This result concerning association membership is a little surprising since in Cameroon the use of social networks seems to be a fact of clans. The coefficient of age is not significant but we observe that the covariate "age-use of networks" (here ParelAge) is significant and negative at 10\%. Hence the effect of age is capture by this covariate. Thus, the hazard function decreases with age, indicating that older individuals are less likely to exit unemployment through social networks. The difficulty that older individuals face in finding work may be attributed to the restrictive hiring standards of employers due to objective and discriminatory factors, such as obsolete skills, health problems, loss of motivation, and discouragement. All these factors may in turn lead to fewer job offers. 


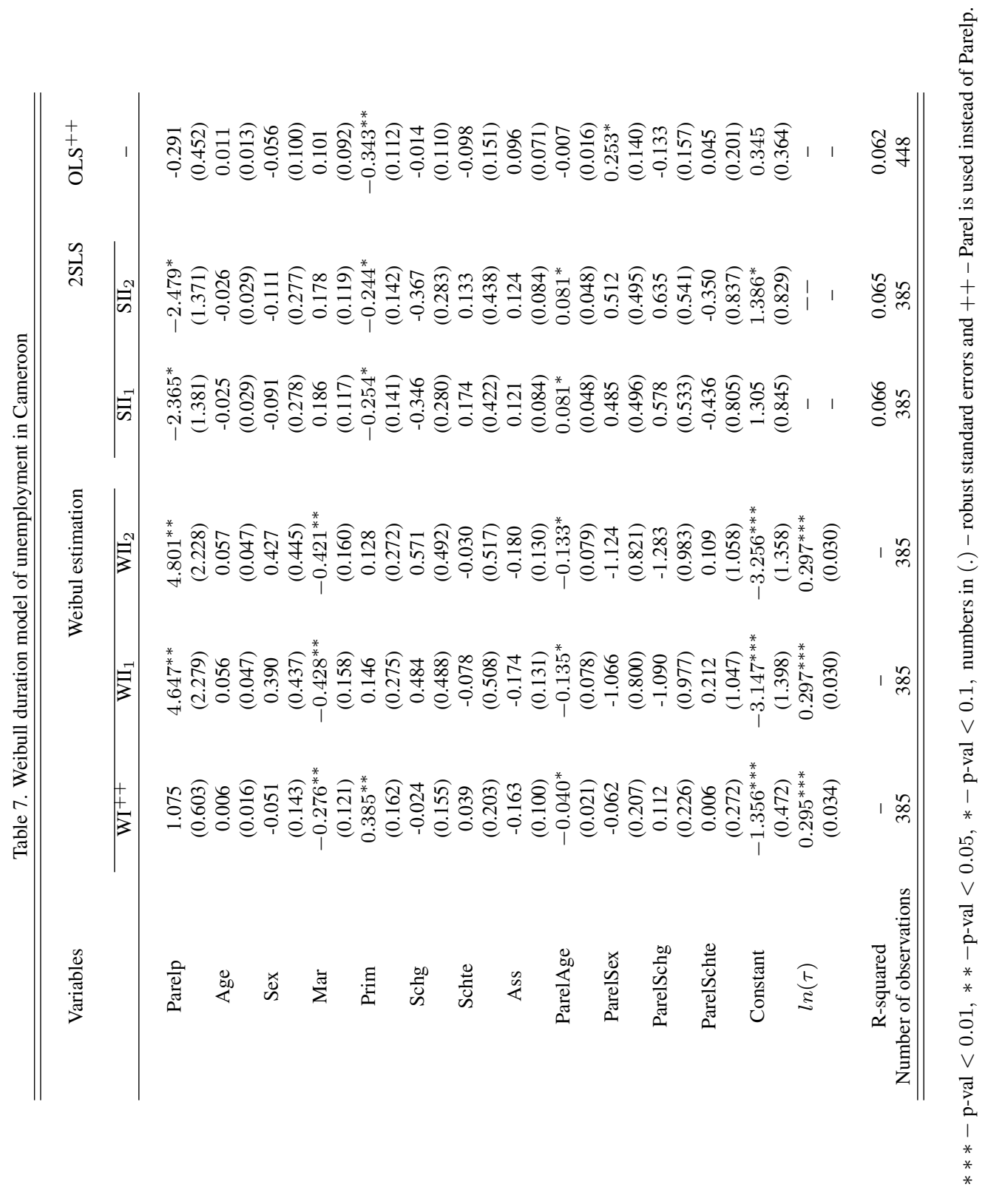


In contrast to sex, education and membership of an association, matrimonial status positively affect the hazard rate. This suggests that individuals who are not married exit unemployment earlier than those who are married, through social networks. Furthermore, our results also indicate that the estimated Weibull parameter $\hat{\tau}=\exp (0.297)=1.35$ and the $t$-test for the null hypothesis $\mathrm{H}_{0}: \tau=1$ is rejected even at the nominal level $1 \%$. This means that the hazard monotonically increases with $t$ and unemployment exhibits a positive duration dependence. Again, this result confirms our previous stylized facts.

\section{Conclusions}

In this paper, we have examined whether the use of social networks (friends and relatives) as a job search strategy matters in Cameroon. After formulating an empirical framework which allowed us to address this issue in a convenient way, we showed that the use of social networks (friends and relatives) is effective in the process of exiting unemployment in Cameroon. More precisely, individuals who use social networks are likely to exit unemployment earlier than those who do not. However, individual characteristics such as sex, education, and association membership, have no effect on the probability of getting a job through social networks. This result concerning association membership is surprising since the use of social networks seems to be a fact of clans in Cameroon. In contrast, the hazard function decreases with age indicating that older individuals are less likely to excite unemployment through social networks. This may be attributed to the restrictive hiring standards of employers due to objective and discriminatory factors (obsolete skills, health problems, loss of motivation, and discouragement). In addition, individuals who are not married are likely to find a job earlier through social networks than those who are married. Furthermore, our results indicate that the hazard function monotonically increases with time and unemployment exhibits a positive duration dependence.

This paper also provides an analysis of factors that determine labor market participation and the use of social networks. We find that the density of the west native population in the center of Cameroon and religion (Protestant) are the only factors that determine the use of social networks. In contrast, individual characteristics such as age, sex, education, membership to an association, determine labor market participation.

\section{Acknowledgments}

The authors would like to thank Professor Mardi Dungey from University of Tasmania, Christian Ebeke from University of Yaoundé 2, Professor Jean-Marie Dufour from McGill University and Professor Lynda Khalaf from Carleton University for several useful comments and suggestions. 


\section{References}

Addison, J., Portugal, P., 2001. Job search methods and outcome. Technical report, IZA.

Breslow, N., 1970. A generalized kruskal-wallis test for comparing k samples subject to unequal patterns of censorship. Biometrika 57, 579-594.

Cahuc, P., Fontaine, F., 2002. On the efficiency of job search with social network. Technical report, IZA.

Calvó-Armengol, A., Jackson, M., 2004. The effect of social networks on employment and inequality. American Economic Review 94(3), 426-454.

Coleman, J., 1988. Capital in the creation of human capital. American Sociological Review 94(14), 95-120.

Coleman, J., 1990. Foundation of Social Theory. Harvard University Press, Cambridge, MA.

Doko, F., Dufour, J.-M., 2008. Instrument endogeneity and identification-robust tests: some analytical results. Journal of Statistical Planning and Inference 138(9), 2649-2661.

Dufour, J.-M., 1997. Some impossibility theorems in econometrics, with applications to structural and dynamic models. Econometrica 65, 1365-1389.

Dufour, J.-M., 2003. Identification, weak instruments and statistical inference in econometrics. Canadian Journal of Economics 36(4), 767-808.

Fleming, T. R., Harrington, D., 1982. A class of rank test procedures for censored survival data. Biometrika 69, 553-566.

Granovetter, M. S., 1974. Getting a Job: A Study of Contacts and Careers second edn. Harvard University Press, Cambridge, MA.

Hall, A. R., Peixe, F. P. M., 2003. A consistent method for the selection of relevant instruments. Econometric Reviews 2(3), 269-287.

Hall, A. R., Rudebusch, G. D., Wilcox, D. W., 1996. Judging instrument relevance in instrumental variables estimation. International Economic Review 37, 283-298.

Hansen, A. B., Hansen, M. E., 2008. Religion, social capital and business bankruptcy in the united states, 1921-1932. Technical report, American University, Washington DC.

Holzer, H. J., 1988. Search method use by unemployed youth. 6, 1-20.

Mantel, N., Haenszel, W., 1959. Statistical aspects of the analysis of data from retrospective studies of disease. Journal of The National Cancer Institute 22, 718-748.

Montgomery, J., 1991. Social networks and labor-market outcomes:toward an economic analysis. American Economic Review 81, 1408-1418. 
Mouw, T., 2003. Social capital and finding a job: Do contacts matter. American Sociological Review $68,868-898$.

Ndongo, Y.-F., Ebene, J.-A., Tegnerowicz, J., 2006. Religion, capital social et réduction de la pauvreté au cameroun: Le cas de la ville de yaoundé. Technical report, MPRA, Munich.

Patacchini, E., Zenou, Y., 2008. Ethnic network and employment outcome. Technical report, IZA.

Peto, R., Peto, J., 1972. Asymptotically efficient rank invariant procedures (with discussion). Journal of the Royal Statistical Society 135, 185-206.

Prentice, R., 1978. Rank tests with right-censored data. Biometrika 65, 167-179.

Putnam, R., ed., 2000. Bowling Alone. Simon and Schuster, New York, New York.

Staiger, D., Stock, J. H., 1997. Instrumental variables regression with weak instruments. Econometrica $65(3), 557-586$.

Stock, J. H., Wright, J. H., Yogo, M., 2002. A survey of weak instruments and weak identification in generalized method of moments. Journal of Business and Economic Statistics 20(4), 518-529.

Stock, J. H., Yogo, M., 2005. Testing for weak instruments in linear IV regression. In: D. W. Andrews, J. H. Stock, eds, Identification and Inference for Econometric Models: Essays in Honor of Thomas Rothenberg. Cambridge University Press, Cambridge, U.K., chapter 6, pp. 80-108.

Sylos Labini, M., 2005. Job search methods and outcomes for the employed and unemployed: An empirical investigation. Technical report, LEM, S Anna School of Advanced Studies, PIZA.

Tarone, R., Ware, J., 1977. Distribution-free tests for equality of survival distribution. Biometrika 64, 156-160.

Wahba, J., Zenou, Y., 2004. Density, social networks and job search methods:theory and application to egypt. Technical report, Research Institute of Industrial Economic.

Wang, J., Zivot, E., 1998. Inference on structural parameters in instrumental variables regression with weak instruments. Econometrica 66(6), 1389-1404.

Webber, A., 2000. Vacancy durations-a model for employer's search. Taylor and Francis Journals: Applied Economics 32, 1069-1075.

Weber, M., ed., 1905. Protestant Ethic and the Spirit of Capitalism. Penguin Book 2002, Routledge, London. 
APPENDIX

\begin{tabular}{|c|c|c|c|c|c|c|c|}
\hline \multicolumn{8}{|c|}{$\mathrm{y}=\operatorname{Pr}($ Ljob $)($ predict $)=.280$} \\
\hline Variables & $\mathrm{dy} / \mathrm{dx}$ & Std. Err. & $\mathrm{z}$ & $P>|z|$ & \multicolumn{2}{|c|}{ [ $95 \%$ C.I. ] } & Mean \\
\hline Age & 0.034 & 0.003 & 11.060 & 0.000 & 0.028 & 0.040 & 23.306 \\
\hline Sex* & 0.117 & 0.025 & 4.780 & 0.000 & 0.069 & 0.165 & 0.514 \\
\hline Prim* & 0.306 & 0.057 & 5.330 & 0.000 & 0.193 & 0.418 & 0.082 \\
\hline Schg* & 0.073 & 0.031 & 2.360 & 0.018 & 0.012 & 0.133 & 0.465 \\
\hline Schte* & 0.180 & 0.044 & 4.100 & 0.000 & 0.094 & 0.266 & 0.152 \\
\hline Mar* & 0.017 & 0.041 & 0.410 & 0.683 & -0.063 & 0.096 & 0.142 \\
\hline Ass* & 0.106 & 0.027 & 3.880 & 0.000 & 0.052 & 0.160 & 0.316 \\
\hline Mst* & -0.010 & 0.041 & -0.250 & 0.806 & -0.090 & 0.070 & 0.101 \\
\hline Fwk* & -0.018 & 0.027 & -0.670 & 0.506 & -0.070 & 0.035 & 0.659 \\
\hline $\operatorname{Prot}^{*}$ & 0.020 & 0.030 & 0.670 & 0.502 & -0.039 & 0.079 & 0.217 \\
\hline Fst* & 0.013 & 0.027 & 0.480 & 0.630 & -0.040 & 0.065 & 0.311 \\
\hline Dst* & -0.028 & 0.060 & -0.470 & 0.637 & -0.145 & 0.089 & 0.050 \\
\hline
\end{tabular}

Table 9. Marginal effects after probit: Determinants of the use of informal contacts

\begin{tabular}{cccccccc}
\hline \hline \multicolumn{7}{c}{$\mathrm{y}=\operatorname{Pr}($ Parel) (predict) $=.508$} \\
Variables & dy/dx & Std. Err. & $\mathrm{z}$ & $P>|z|$ & & [95\% C.I. ] & Mean \\
\hline Age & -0.008 & 0.003 & -2.410 & 0.016 & -0.014 & -0.001 & 26.840 \\
Sex* & -0.036 & 0.051 & -0.700 & 0.486 & -0.137 & 0.065 & 0.605 \\
Prim* & 0.200 & 0.072 & 2.790 & 0.005 & 0.059 & 0.341 & 0.144 \\
Schg* & 0.085 & 0.061 & 1.390 & 0.164 & -0.035 & 0.205 & 0.372 \\
Schte* & 0.081 & 0.072 & 1.120 & 0.265 & -0.061 & 0.223 & 0.177 \\
Mar* & -0.110 & 0.064 & -1.710 & 0.087 & -0.236 & 0.016 & 0.284 \\
Ass* & 0.103 & 0.051 & 2.010 & 0.045 & 0.002 & 0.203 & 0.435 \\
Mst* & 0.056 & 0.089 & 0.630 & 0.532 & -0.119 & 0.231 & 0.091 \\
Fwk* & -0.032 & 0.053 & -0.590 & 0.552 & -0.136 & 0.073 & 0.563 \\
Prot* & 0.137 & 0.058 & 2.370 & 0.018 & 0.024 & 0.250 & 0.228 \\
Fst* & 0.066 & 0.056 & 1.170 & 0.241 & -0.044 & 0.176 & 0.298 \\
Dst* & 0.370 & 0.085 & 4.370 & 0.000 & 0.204 & 0.536 & 0.049 \\
IMRP & 0.093 & 0.059 & 1.570 & 0.116 & -0.023 & 0.209 & 0.902 \\
\hline \hline
\end{tabular}

$(*)-\mathrm{dy} / \mathrm{dx}$ is for discrete change of dummy variable from 0 to 1 . 


\section{School of Economics and Finance Discussion Papers}

2011-04

2011-03

2011-02

2011-01

2010-12

2010-11

2010-10

2010-09

2010-08

2010-07

2010-06

2010-05

2010-04

2010-03

2010-02

2010-01

Do Contact Matter in the Process of Getting a Job in Cameroon? Firmin Doko Tchatoka and Urbain Thierry Yogo

Subset Hypotheses Testing and Instrument Exclusion in the Linear IV Regression, Firmin Doko Tchatoka

First home Buyers' Support Schemes in Australia - Results Spreadsheet, Mardi Dungey, Graeme Wells and Sam Thompson

First home Buyers’ Support Schemes in Australia, Mardi Dungey, Graeme Wells and Sam Thompson

Financial Crises in Asia: Concordance by Asset Market or Country?, Mardi Dungey, Jan P.A.M. Jacobs and Lestano

Innovation Contracts with Leakage Through Licensing, Shane B. Evans

Franchise Contracts with Ex Post Limited Liability, Shane B. Evans

Menus of Linear Contracts in Procurement with Type-Dependent Reservation Utility, Shane B. Evans

Decomposing the Price Effects on the Cost of Living for Australian Households, Paul Blacklow

Modelling the Time Between Trades in the After-Hours Electronic Equity Futures Market, Mardi Dungey, Nagaratnam Jeyasreedharan and Tuo Li

Cojumping: Evidence from the US Treasury Bond and Futures Markets, Mardi Dungey and Lyudmyla Hvozdyk

Assessing the Impact of Worker Compensation Premiums on Employment in Tasmania, Paul Blacklow

Non-Linear Pricing with Homogeneous Customers and Limited Unbundling, Hugh Sibly

Detecting Contagion with Correlation: Volatility and Timing Matter, Mardi Dungey and Abdullah Yalama

From Trade-to-Trade in US Treasuries, Mardi Dungey, Olan Henry and Michael McKenzie

Economic Assessment of the Gunns Pulp Mill 2004-2008, Graeme Wells

Copies of the above mentioned papers and a list of previous years' papers are available from our home site at http://www.utas.edu.au/ecofin 